\title{
Conceptual Blending in Translation of English Neologisms
}

\author{
Jian-yu Zheng \\ School of Translation Studies \\ Jinan University \\ Zhuhai, Guangdong 519070, China
}

\begin{abstract}
As the progress of the globalization and the advancement of new technologies, there are more and more new members to the vocabulary of human language. When new words are translated into Chinese, there is more than mere translation that is going on. It is actually a very complicated cognitive process.Conceptual Blending theory sheds new light upon the translation of neologisms. This thesis mainly deals with translation of English new words and terms into Chinese. In the conceptual blending network, English takes up one input space and Chinese takes up another. In order to render a good translation for the new words, a little creation is required. Elements and frameworks from both inputs are selectively projected into the blend, where they are dynamically integrated. Then, a novel structure (translation) is constructed based are the projected framework and elements. Thus, previously meaningless combination of Chinese characters is endowed with new purport.
\end{abstract}

Keywordscognitive process, translation of neologism, conc eptual blending theory, input space, novel structure.

\section{INTRODUCTION}

Conceptual Blending, developed by Gilles Fauconnier and Mark Turner, is a cognition theory. According to this theory, elements and vital relations from diverse scenarios are "blended" in a subconscious process known as conceptual blending. It is ubiquitous to everyday thought and language. Insights obtained from these blends lay the very root of creative thinking.

The thesis mainly studies the process of conceptual blending when translating those English new words and terms whose Chinese counterparts cannot be readily found. The translation of such words and terms requires a little creation and innovation. The inputs of the original language and the target language are projected into the blended space, and then reconstructed into an emergent structure, i.e. the translated term which cannot be found in either of the existent vocabulary repositories.

\section{TYPES OF CONCEPTUAL BLENDING AND TRANSLATION}

In this thesis examples are cited from English Chinese translation.) In next section, the thesis uses mirror, single scope and double scope networks to explain translation of different styles.

\section{A. Mirror Network and Translation (Equivalence)}

As is explained in the previous section, in Mirror network all spaces share an organizing frame that specifies the nature of the relevant activity, events and participants. The input spaces mirror each other in having this same frame. This type applies specifically in the "equivalence" phenomenon in translation.

Equivalence is the phenomenon that an equivalent of the source text can be found in the target language. For example, in Water (English) - 水/shui (Chinese), which can be understood as a mirror network. We can find exact same framework in the input I (English) and the input II (Chinese). The shared framework is mirrored into the blend and then builds up the translation. As in the Water 水/shui example: water in English is "a clear, colorless, odorless, and tasteless liquid, $\mathrm{H} 2 \mathrm{O}$, essential for most plant and animal life and the most widely used of all solvents. Freezing point $0^{\circ} \mathrm{C}\left(32^{\circ} \mathrm{F}\right)$; boiling point $100^{\circ} \mathrm{C}\left(212^{\circ} \mathrm{F}\right)$; specific gravity $\left(4^{\circ} \mathrm{C}\right) 1.0000$; weight per gallon $\left(15^{\circ} \mathrm{C}\right)$ 8.338 pounds (3.782 kilograms)" ; while in Chinese “水” has similar framework: “以雨的形式从云端降下的液体, 无色无味且透明,形成河流、湖泊和海洋, 分子式为 $\mathrm{H} 2 \mathrm{O}$, 是一切生物体的主要成” (高级汉语词典).

When translating, the framework and elements shared in the two inputs are projected into the blend and construct the translation, and the translated text is completely equivalent to the original text.

For example:

English: Blood is thicker than water.

Chinese: 血浓于水

English: Jack goes to school at eight o'clock everyday.

Chinese: 杰克每天八点去上学

English: apple

Chinese: 苹果

English: speak well of me

Chinese: 说我好话

For many hundreds of years, translation has been understood as simply finding equivalents of original language in the target language. However, as it turns out, translation involving two languages with distinct linguistic

\footnotetext{
1 "water." The American Heritage Dictionary of the English Language, Fourth Edition. Houghton Mifflin Company, 2004. Answers.com 13 Oct. 2007. <http://www.answers.com/topic/water>
} 
features and cultural associations, equivalence only occupies a part of translation activities.

\section{B. . Single - Scope Network and Translation}

Single - scope network is composed of two different frameworks. The blended space inherits the framework from one input space, and the other one projects input elements into the blend. In translation, two phenomena, foreignization and domestication, can be understood as this type of network. In other words, single scope network has two representations in the practice of translation.

\section{INHERITING FRAMEWORK OF ENGLISH (FOREIGNIZATION)}

Foreignization can be understood as a single - scope network blending, taking the original text, English, as a reference and inheriting English the style and model as the organizing framework in the blend.

Input Space I (English) contains the English linguistic framework and the text to be translated; Input Space II contains the Chinese linguistic framework carrying the meaning that connects to Input Space I. When translation happens, only one framework, English semantic framework from Input I, is projected into the blend. Then the Chinese characters or words are borrowed from the Chinese Input. But the meaning of such carried-over terms and words are not inherited from the same input. Instead the semantic meaning is imported from the English input.

For example:

English: Shed crocodile tears to me

Chinese: 在我面前掉你那鳄鱼的眼泪

When "crocodile tears" is being translated, the Chinese elements, the literal counterpart of "crocodile tears”, “鳄鱼 的眼泪” are projected in the blend. Nevertheless, the meaning of the term is not automatically carried over from the same input. Instead, the semantic meaning is inherited from the English, or in other words, the semantic framework of the blend is from English input. Then in the emergent structure, we have got the translation, “鳄鱼的 眼泪”. In doing so, the cognitive association of the English term: when crocodiles shed tears, they intend to set traps for prays. The underlying association, "hypocrisy" is carried over from the English input. By introducing into Chinese the novel way of expression, e.g., “鳄鱼的眼泪”, the translator has successfully enriched the target language (in this case Chinese).

\section{INHERITING FRAMEWORK OF CHINESE (DOMESTICATION)}

Well, when a translator is doing translation and no easy equivalence can be found in the target language, he has another option: using the organizing frameworks from Chinese language to render the translation, also known as domestication.

This type of translation is also a single - scope network blending. In Input Space I (English) is the English linguistic framework, the text to be translated; in Input Space II is the Chinese linguistic structure carrying the meaning that connects to Input Space I. When translation happens, only one framework is projected into the blend. But in this case it is the Chinese linguistic framework from Input II. And then the Chinese characters or words that carry the implied meaning of the English text are projected. When the projected is dynamically integrated, the completed emergent structure is the translation, with the Chinese linguistic expression way as the organizing framework.

For example:

English: Shed crocodile tears to me

Chinese:在我面前假慈悲

English: a flash in a pan

Chinese: 是花一现

English: One rotten apple spoils the whole barrel.

Chinese: 一粒老鼠屎坏了一锅粥

\section{A. Double-Scope Network Blending}

Sometimes, translation involves two frame networks at the same time. This type of translation can be understood as a double - scope network blending. The two input spaces of the double - scope network have different frameworks. The organizing framework in the blend space is composed by integrating the two frames in both input spaces.

Similar with the above mentioned three types of translation, Input Space I (English) contains the English linguistic framework and the text to be translated; Input Space II contains the Chinese linguistic structure carrying the meaning that connects to Input Space I. Here the difference happens when the projection starts. Parts of both frameworks in input spaces are projected into the blend to form a novel framework.

For Example:

English: Juda's kiss

Translation: 犹大之吻, 居心险恶

Translation has always been understood as an "objective" process. This is misled by the fact that the "meaning" of a word is objective and truth-conditional, so must be act of transforming meaning from one language to another. Bringing cognitive linguistics and conceptual blending theory into discussion sheds new light on the fact that translation is an act that involves an integration of various concepts and cultural patterns. Translated text is, thus, the blended result of the cultural schemes of the two languages. With the conceptual blending network, we can better understand the creativity and diversity of translation.

\section{THE BENEFITS OF EXPLAINING TRANSLATION OF NEW ENGLISH WORDS INTO CHINESE}

\section{A. Translation as Cognition}

First using blending theory clearly illustrates that translation of English neologisms is a cognitive process.

As the previous section just illustrated, the process of translation of new English words activates various mental spaces and triggers a dynamic cognitive integration of schemes and elements. As in the example of “Google - 谷 
歌”, the semantic scheme of the brand name "Google" and its Chinese counterpart “谷歌” are creatively “blended” in the following way: "a search engine that processes huge amount of information" + "echo of songs in the valley" = "a search engine so powerful that you type a word in the key word filed, it 'echoes' back huge amount of related information". This is a highly cognitive process, the cognitive scheme of English input space is fused with the one of Chinese input, bringing about a emergent entity that can stimulate a new type of cognition of the word “谷歌”.

Similar with translation in general, translation of English new words involves two rounds of cognition.

The first round of cognition is by the translator. As a human being, a translator lives in a sensual world. $\mathrm{He}$ gains experiences from sensory and perspective inputs which are stored in the brain. When triggered by the external stimuli, like a new word, the stored experiences can be triggered to produce vivid images in his mind. During translation, these experiences and images are more or less reflected in the translated text. As pointed out by Zhou Hongmin in his article published in "Foreign Languages and Their Teaching", translated texts are the materialized form of the cognition processes by the translator and the cognition processes can be presented by the translated text in many ways. (Zhou 49)

The second round of cognition takes place in the readers' mind: the textual meanings presented by translator trigger in the mind of readers certain schema (Zhou 49). However, cognitive model varies according to our different growing environment. For examples, Chinese have a unique birth mentality, "more offsprings mean more happiness" (多子多福). We don't have a cognitive model for cricket because it is not part of our lives. Therefore the cognitive model for an experience relies much on our cultural model and cultural model is embedded into cognitive models.

Cognitive models for particular domains ultimately depend on so-called cultural models. In reverse, cultural models can be seen as cognitive models that are shared by people belonging to a social group or subgroup...

... the term "cultural model" emphasizes the uniting aspect of its being collectively shared by many people.(Ungerer 50)

The cognition equivalence is that these schemas should be the same with the triggered schema that the original texts have affected in the mind of the readers. Due to the cognition model differences between cultures, such equivalence is almost impossible to strike. Therefore, to achieve an optimized cognitive effect, translator needs to take into consideration the cognition frameworks of readers of two languages. Or as explained by Conceptual Blending, elements and schemes are selectively projected from two input spaces to form the emergent structure in the blended space.

Using conceptual blending theory to explain translation of new words can help to decipher the psychological activities during translation. As a reader of the original text, translator holds the same ground as the readers who speak the language of the original text. But as the in-built mentality of his own culture, the framework triggered doesn't completely equals the framework triggered by readers of the same language. Different interpretation can be made to the same language symbols. If the translator uses his framework to construct translation, his readers will trigger similar framework. In the end the original text and the translated text have two different effects. Although a qualified translator should have bi-cultural frameworks, translation as a cognitive process, such deviation or differentiation is unavoidable. Translated version is the productized cognition, instead of the equivalence of the original text.

Translation of English neologisms into Chinese is a cognition process that involves two different languages and cultures. It is a complicated cognitive process.

\section{B. Emergent Structure and "Novelty" in Translation}

Translating an English neologism to Chinese is more often than not a difficult task, because there is no ready equivalent that a translator can pick up right away. In this special translation task, the translator is required to use a little creation and innovation in order to render a Chinese qualified translation.

Why is “coca cola - 可口可乐” a typical good translation? Because it is a double- scope blending that integrate the English and Chinese input perfectly. On one hand, “可口可乐” resembles the phonetic feature of the original word. On the other, the semantic meaning ("delicious and delightful") of the four Chinese characters can be associated with coca cola. In fact the association of "delicious and delightful" is perfectly blended with the referred meaning of "a type of soft drink". Formerly, this perfect translation is explained as “音意结合”, or equivalence at both phonetic and semantic levels. Nevertheless, such an explanation cannot account for the "creativeness" involved in this translation. Where does the association of "tasteful and delightful" come from? This is not what the original term "coca cola" refers to but something new brought from Chinese. However, this mysterious gap can be filled by conceptual blending theory.

Conceptual blending involves four mental spaces. Mental spaces are the collection that contains all kinds of information. It is composed of framework and cognition model. They are inter-connected and can be modified as our thinking or text extends. As in a translation conceptual blending network, English and Chinese take up two Input Spaces. The Generic Space contains the shared frames of the two inputs. The creation and innovation happens in the fourth mental space, the blended space. The projected elements and frameworks from the two inputs are integrated here in this fourth space and then form something novel, the emergent structure, for example, “可 口可乐” means “a brown colored soft drink that is tasteful and that brings you delight". This new structure doesn't exist in the English input space, because in the English input space is only composed of the framework "coca cola, a soft drink". The new structure doesn't exist in the 
Chinese input either. The Chinese input contains the framework “可口可乐, meaning tasteful and delightful”. Therefore, the emergent structure is the resulted "novelty" and "creativeness" after conceptual blending.

Hence, the novelty, creativeness brought about during translation of neologisms can best be explained by the "emergent" structure in conceptual blending. Insights obtained from blending constitute the products of creative thinking. Similarly, the dynamic integration process in the blended space can account for the creative cognitive process of translation of new words.

For centuries, translation had been understood as word to word equivalence, while the non equivalent and novelty are often neglected. conceptual blending theory can account for equivalence. Moreover, it offers an enlightening perspective to understand the "creative" language usage spawned during translation.

\section{Process in Translation}

Using conceptual blending to explain translation of English neologisms has another benefit. It illustrates very clearly the process: the meaning composition process (microscopically) and assimilation process (macroscopically).

First, conceptual blending illustrates very clearly the blending process: composition, completion and elaboration. During blending, elements and frameworks are first projected. Then, they are integrated together the form the emergent structure. Lastly, the emergent structure can be elaborated, also know as "running" the blend. When applied in explaining translation of English neologisms, the projection of various elements, and integration of frameworks can be elaborated in detail. Therefore, the translation process is explained very clearly. Most important of all, it gives a clear view on how different aspects of the semantic meaning of the translated work are inherited and constructed. For example, in “cocoa - 可可”, the semantic meaning is brought over from English input; while in "shampoo-香波”, the meaning is the integrated result of both inputs.

Second, using conceptual blending theory to explain the translation of new words can cover the whole process, from the first stage the new term is introduced to Chinese as being an exotic concept, to the stage it is commonly used and regarded as the official translation for the term, and to the final stage the translation is regarded as equivalent counterpart of the English original as one of the Chinese vocabulary. In the final stage, the translation is not longer a translation: it is regarded as a natural part of the Chinese language. It is even used to construct other language elements as part of the input from Chinese language.

As in the example of "沙发(sofa)", it was a novel thing when it was first introduced. At the first stage it is regarded as a translation for a piece of foreign furniture. It can be understood as a double - scope network blending. The integrated organizing framework is: "a piece of furniture for sitting and that is made of springs (from
English Input), which is very soft (from Chinese Input)". After the furniture is widely used in China, “沙发” has become a common word. A solid connection between “sofa” and “沙发” is built up. The Chinese word is viewed as an equivalent to “sofa". Today, the fact that “沙发” is a translation is often forgotten. It has become a lexicon in Chinese language and is even used as an input itself to form new translation: as in "沙发土豆(couch potato)".

\section{TRANSLATION OF ENGLISH NEOLOGISMS IN DIFFERENT STYLES OF TEXTS}

In this section, the thesis demonstrates with abundant examples how different types of Conceptual Blending networks are applied to translation of English neologisms. The examples are selected from three sources: news articles, scientific writings and brand names.

Neologisms tend to occur more often in those languages in which a lot of new information is communicated. Nowadays, English is used as the universal language with a large number of speakers. Being one of the most active languages, the English language witnesses new words and terms coined almost every day. These English neologisms enrich the language and to some extent reflect the changes taking place in our world.

Where do these new lexicons and terms come from? New lexicons and terms are coined at the same time people make discoveries, invent new things, raise new questions, solve problems, give new ideas and so on so forth. Since neologisms bear the most prominent feature of "neo", or novelty, they are most often found in three contexts: newspaper reports, scientific writings and brand names. The translation of the three texts is the major source of introducing new words or terms into the target language.

\section{A. Translation of English Neologisms in News Articles}

Scientific and technological breakthroughs, social revolutions and progresses of civilization, all of these "heart beats" of times are recorded in the language we use. Newspaper is a medium where we can find a concentration neologisms as well as new ideas, concepts, and movements of mankind. In this part, the thesis cites some examples of neologisms used in newspaper articles and explores how they can be explained by Conceptual Blending. All examples in this part are quoted from $A$ Handbook of Latest Chinese Idioms (or Chinese name as 汉英最新特色词汇, collected and compiled by ChinaDaily.com.cn).

1) Simplex Network: Inheriting Framework from English Input

In this type of translation, the blended space inherits the semantic meaning of the original word as the organizing structure, and inherits two Chinese characters from Chinese input. For example:

\section{mortgage loan: 按揭}

English: When granting mortgage loans to individuals, banks should closely evaluate any assets being pledged. 
Chinese: 对个人发放按揭贷款时, 银行须对抵押财 产做严格估价。(ChinaDaily.com.cn 3)

To translate “mortgage” as “按揭” is a simplex network blending. The semantic scheme from the English Input is projected into the blend as the organizing framework. Then two Chinese characters with similar phonetic features from the Chinese input are projected as two elements. These two Chinese characters, “按揭”, don't mean anything in the Chinese language. Or, in other words, they don't have a semantic scheme. Their spelling and phonetic features are projected only as elements to be integrated with the organizing structure from the English input. After the projected elements and framework being integrated together in the blended space, an emergent structure is constructed. The emergent structure is the translation for "mortgage". It is “按揭” which has the Chinese spelling and pronunciation but actually means "a temporary, conditional pledge of property to a creditor as security for performance of an obligation or repayment of a debt”, or “给予债权人临时的、有条件的财产抵押, 以此作为履行责任或偿还债务的保证” in Chinese. ("按 揭" was introduced from Hongkong and the term in Cantonese sounds similar to "mortgage").

2) Single - Scope: Inheriting English Semantic Framework

Another type of single - scope network blending is the case in which Chinese imported characters have meanings have a clear referred to meaning in Chinese language. The difference is that their meaning is not carried over, while the English semantic structure still forms the organizing framework of the blend. For example:

white paper: 白皮书

White paper is an authoritative report about a major issue given by government, usually in U. S. or U. K. It is bound in white, so it is called "white paper", for example in Churchill White Paper, 1922. White paper is translated into Chinese as “白皮书”, which literally means in Chinese "a book with a white cover". This is the semantic frame for “白皮书” in Chinese input, but it is not projected into the blend. Instead, the English semantic framework, "white paper, a government report" ${ }^{3}$ is projected into the blend as the organizing framework. In addition, the spelling and phonetic features of Chinese characters “白, 皮, and 书” are projected from the Chinese input to be integrated with the organizing structure. After integration, the emergent structure or the translation is finished in the blended space, i.e., “白皮书” which has the

2 "mortgage." The American Heritage Dictionary of the English Language, Fourth Edition. Houghton Mifflin Company, 2004. Answers.com 03 Sept. 2007.

<http://www.answers.com/topic/mortgage>

3 "white paper." The American Heritage Dictionary of the English Language, Fourth Edition. Houghton

Mifflin Company, 2004. Answers.com 03 Oct. 2007. <http://www.answers.com/topic/white-paper>
Chinese spelling and pronunciation but actually means "government reports".

English: In its 2001 White Paper on Trade, Japan admitted for the first time that it is losing its leading position in the Asian economy.

Chinese: 日本政府在 2001 年贸易白皮书中首次承 认日本正在失去亚洲经济中的主导地位。 (ChinaDaily.com.cn 6)

3) Double - Scope: Blending English and Chinese Semantic Frameworks

In translation of this type, frameworks from both English and Chinese inputs are projected. The projected frames are integrated to a new one in the blended space. Emergent structure is the integration of the blended framework and other projected elements from two inputs. For example: 滋病

English: By the end of 2002, there were 42 million HIV carriers in the world. In 2002 alone, nearly three million people died of AIDS and around five million became infected with HIV.

Chinese: 到 2002 年底, 全世界共有 4200 万艾滋病 毒携带者。仅 2002 年就有近 300 万人死于艾滋病, 大 约 500 万人感染艾滋病毒。(ChinaDaily.com.cn 1)

AIDS is a "disease caused by a blood-borne virus (called human immunodeficiency virus or HIV) that disrupts the body's normal immune responses" ${ }^{4}$. In Chinese it is translated as “艾滋病”. How is the translation understood as a double - scope conceptual blending?

There are two frameworks involved in the blending process. The first is the English semantic structure of "AIDS": a disease caused by a blood-borne virus (called human immunodeficiency virus or HIV) that disrupts the body's normal immune responses. The other one is the Chinese semantic structure of “艾滋病”: “a infectious disease", ( “滋” in Chinese has meaning of "increase", "grow", and "permeate" and “病" is disease in Chinese). The organizing framework in blend is the integrated result of the two. Besides, the spellings and phonetic features of “艾”, “滋” and “病” are projected as elements. When the projected are all integrated together, the emergent structure is complete, i.e., “艾滋病” means “全称为获得性免疫缺 陷综合征, 是人体感染了人类免疫缺陷病毒 (HIV, 又 称艾滋病病毒）所导致的传染病”.

\footnotetext{
4 "acquired immune deficiency syndrome." Food and Fitness: A Dictionary of Diet and Exercise. Oxford University Press, 1997, 2003. Answers.com 03 May. 2007. <http://www.answers.com/topic/acquiredimmune-deficiency-syndrome-2>
} 


\section{B. Translation of English Neologisms in Scientific Articles}

In science readings, the new findings and inventions are introduced, therefore, quite a few neologisms can also be found in this style of writing.

\section{1) Mirror Network Blending}

IP (Internet Protocol): IP

English: Real-time video therefore is not as robust as non-real-time video in the presence of typical IP degradations such as packet loss, jitter and delay.

Chinese: 因此, 实时视频在典型的 IP 递降中, 如包 丢失、随机噪声和延迟方面, 不如非实时系统强大。 (宋, 电子通信篇 21)

In this case, the translator directly uses the original English word as its Chinese translation. It is a Mirror network blending. All spaces share the same scheme, that is, IP which stands for Internet Protocol or 互联网协议 in Chinese.

2) Single - Scope Network Blending (Inheriting Organizing Framework from English)

\section{Bluetooth: 蓝牙}

English: Bluetooth is mainly oriented toward connections between closely connected devices as a substitute for data transfer cables; IEEE 802.11, as an extension to or substitute for cables LANs, is devoted to connections among computers.

Chinese: 蓝牙主要应用于距离很近的设备, 从而作 为数据传输线的提到品; IEEE 802.11 用来做计算机之 间的连接, 作为局域网的一种延伸或替代。(宋, 电子 通信篇 $32-33$ )

In this example, the translation can be understood as single - scope network blending. In the blending process, the semantic meaning of the English word (a wireless personal area network (WPAN) standard for short-range transmission of digital voice and data ${ }^{5}$ ) is projected as the organizing framework, while the semantic meaning (蓝色 的牙齿) in the Chinese input is discarded. After the organizing structure is integrated with projected Chinese characters, the emergent structure is finished. It is “蓝牙”, meaning “无线数据和语音传输的开放式标准”.

\section{CONCLUSION}

Translation is a complicated process which involves a large number of elements and factors from both the target and source languages. Therefore it cannot be easily concluded as decoding and encoding or finding some equivalents in target languages. Instead it is a highly complex cognitive process that calls upon inputs from both languages and many automatically triggered cultural associations. And then in the blended space, all of these

\footnotetext{
5 "Bluetooth." Computer Desktop Encyclopedia. Computer Language Company Inc., 2007. Answers.com 03 Oct. 2007. <http://www.answers.com/topic/bluetooth>
}

frameworks, elements and cultural schemes are integrated to construct a novel structure, the translation.

The translation of neologisms is more of the case, since no existing counterparts can be found in the target language. To translate them requires some "creation", or in other words, conceptual blending.

Taking a conceptual blending point of view, the thesis gives a new perspective to understand and explain translation of English neologisms. Insights gained are contributive to the translation studies. Yet, of course, this thesis has its limitations. There are some areas that it is unable to cover. What affects the adoption of different conceptual blending strategy when we are translation neologisms? Does the formation of neologisms affect the adoption translation strategy? These are among the questions that are still to be answered. The completion of the thesis is just a beginning. The author hopes the findings in the thesis can inspire new thoughts and ideas to solve more questions in translation studies.

\section{Reference}

[1] Brandt, L. and Brandt, P. A. "Making Sense of a Blend- A cognitive-semiotic approach to metaphor." University of Aarhus. 5 June. 2007 <www.hum.au.dk/semiotics/docs2/pdf/brandt\&brandt/making_sen se.pdf>

[2] Coulson, Seana. Semantic Leaps: Frame-Shifting and Conceptual Blending in Meaning Construction. Cambridge: Cambridge University Press, 2006.

[3] Crush, R. and Mandelblit, N. "Blending in Language, Conceptual Structure, and the Cerebral Cortex." 5 June. 2007 <http://citeseer.ist.psu.edu/cache/papers/cs/3716/http:zSzzSzwww. artsci.wustl.eduzSz rgrushzSzmisczSz..zSzpaperszSzblendzSzblen d.pdf/blending-in-language-conceptual.pdf

[4] Dedre, G. Keith, James H and Boicho N. K. The Analogical Mind: Perspectives from Cognitive Science. Cambridge: MIT Press, 2006.

[5] Fauconnier, Gilles. "Conceptual Integration." 2001. 8 Oct. 2007. <http://www.ifi.unizh.ch/ailab/people/lunga/Conferences/EDEC2/i nvited/FauconnierGilles.pdf>

[6] Goguen, J. A. and Harrell, D. F. "Style as a Choice of Blending Principles." $\quad 5 \quad$ June. 2007 <www.cs.ucsd.edu/ goguen/pps/style04.pdf>

[7] Lakoff, G. and Johnson, M. Metaphors We Live By. Chicago: University of Chicago Press, 1980.

[8] McElhanon, Kenneth A. "From Simple Metaphors to Conceptual Blending: The Mapping of Analogical Concepts and the Praxis of Translation." Journal of Translation, 2006, 2(1). 5 June. 2007 <www.sil.org/siljot/2006/1/48002/siljot2006-1-03.pdf>

[9] Turner, Mark. "Design for a Theory of Meaning." The Nature and Ontogenesis of Meaning. 1994. Lawrence Erlbaum Associates. 5 June. 2007 <http://markturner.org/design.html>

[10] Turner, Mark. The Literary Mind. Oxford: Oxford University Press, 1996.

[11] Ungerer, F. \& Schmid, H. J. An Introduction to Cognitive Linguistics. Beijing: Foreign Language Teaching and Research Press, 2001.

[12] ]Wang, Bin. "Metaphorical Terms for Translation." Perspectives: Studies in Translatology, 2003, 11(3): 189-195. 